\title{
Spatio - Temporal Analysis of Ground Water Levels in NCT Delhi (1990-91 to 2011-12)
}

\begin{abstract}
Sutandra Singha
Centre for Russian and Central Asian Studies, School of International Studies, Jawaharlal Nehru University, New Delhi, India
\end{abstract}

\begin{abstract}
On account of the near universal availability, dependability and low capital cost; ground water is the most preferred source of water in various sectors in India. Increasing demand of ground water followed by indiscriminate extraction in various parts of the country, indifferent to the recharging capacities of aquifers and other environmental factors are creating pressure on this water resource. In recent years, National Capital Territory (NCT) of Delhi is experiencing ground water crisis due to rapid urbanization, population growth, increasing demand in industrial sectors and farm houses. Ground water undergoes further stress when it is extracted during drought periods or unplanned withdrawal from subsoil aquifer. Depending upon the availability of continuous set of data, a spatio-temporal analysis of dynamic ground water levels of four selected districts of NCT Delhi - New Delhi, South-West Delhi, South Delhi and North Delhi have been attempted on the basis of the methodology namely Ground Water Hydrographs (1990-91 to 2011-12) both for the pre monsoon and post monsoon time period. Based on the overall assessment of dynamic ground water resources, a broad ground water management plan has been proposed.
\end{abstract}

KEYWORDS: Ground water, urbanization, population growth, subsoil aquifer, wround water hydrographs 


\section{INTRODUCTION}

National Capital Territory of Delhi (latitude: $76^{\circ} 60^{\prime} \mathrm{E}$ to $77^{\circ} 30^{\prime} \mathrm{E}$; longitude: $28^{\circ} 0^{\prime} \mathrm{N}$ to $28^{\circ} 60^{\prime} \mathrm{N}$ ) occupies an area of $1486 \mathrm{~km}^{2}$ with a population density of 11297 persons/sq.km. Total water requirement for the year 2010 was 1000 million gallons per day (MGD) and the Delhi Jal Board supplied around 850 MGD including around 100 MGD from groundwater (Shekhar et al., 2009).

In future, both of the demand and the supply can be assumed to increase followed by intensification of already existed deficit in water supply. Such water deficit of NCT Delhi can be partially augmented through the over exploitation of groundwater resources.

Availability of groundwater throughout the NCT Delhi is controlled by the variations in hydrogeological conditions. In the NCT Delhi area, the major sources of ground water are aquifers of older alluvium (fine to medium sand) and newer alluvium (medium to coarse sand) along the Yamuna flood plain and, the hard rock formations occupied by quartzite, inter-bedded with mica schist belonging to Delhi Super Group (Khan et al., 2014).

The depth to water in the Delhi state varies greatly from 1.2 MBGL (meters below ground level) in the Yamuna flood plain) to more than 64 MBGL in the southern part of the Delhi Ridge area. Recently, the groundwater is declining in majority of the areas of Delhi, especially in south and south-west Delhi where the rate of decline is as high as 1.7 to 2 meters/year due to increasing demand and lack of proper recharge (DPCC 2011).

Among the nine districts of NCT Delhi, four districts- New Delhi, South-West Delhi, South Delhi and North Delhi have been selected for this study (Figure: 1), depending upon the availability of continuous data both in terms of rainfall and ground water level for the time period of 1990-91 to 2011-12.

\subsection{Research Questions}

This paper intends to focus on the following questions:

1. What are the trends of ground water level fluctuations with respect to rainfall in the four selected districts of NCT Delhi from 1990-91 to 2011-12 ?

2. What are the controlling factors behind such trends?

3. What are the measures to improve the ground water situation in these four districts?

\subsection{Hypothesis}

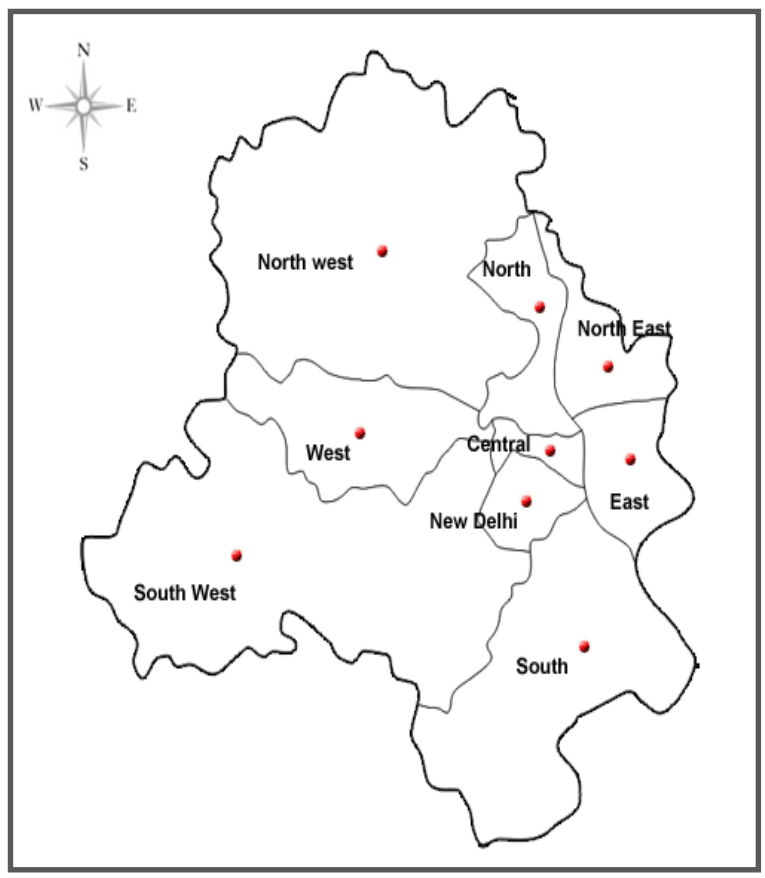

Figure 1. District Map of NCT of Delhi

Source: Delhi Tourism, Government of NCT of Delhi, 2013

Before proceeding to the analysis, the following points have been considered as hypotheses: 
1. Climate and physiography have significant impact on spatial and temporal variation of ground water level in NCT Delhi.

2. Due to increasing population growth and urbanization, ground water is under pressure in some districts of Delhi.

\section{RESEARCH METHODOLOGY}

In the present study, data was collected from the following sources:

1. Monthly rainfall data for the Safdarjang Weather Station have been collected from The Regional Metrological Office of Indian Metrological Department (IMD), New Delhi.

2. Ground water level fluctuation data of the monitoring stations - Safdarjang and Lodhi Garden Dug Well (New Delhi), Shekhawati Line Piezometer (South-West Delhi), Madan Gir and Kidwai Nagar Piezometer (South Delhi), Banda Bahadur and MKT Dug Well (North Delhi) have been collected from Central Ground Water Board (CGWB), New Delhi.

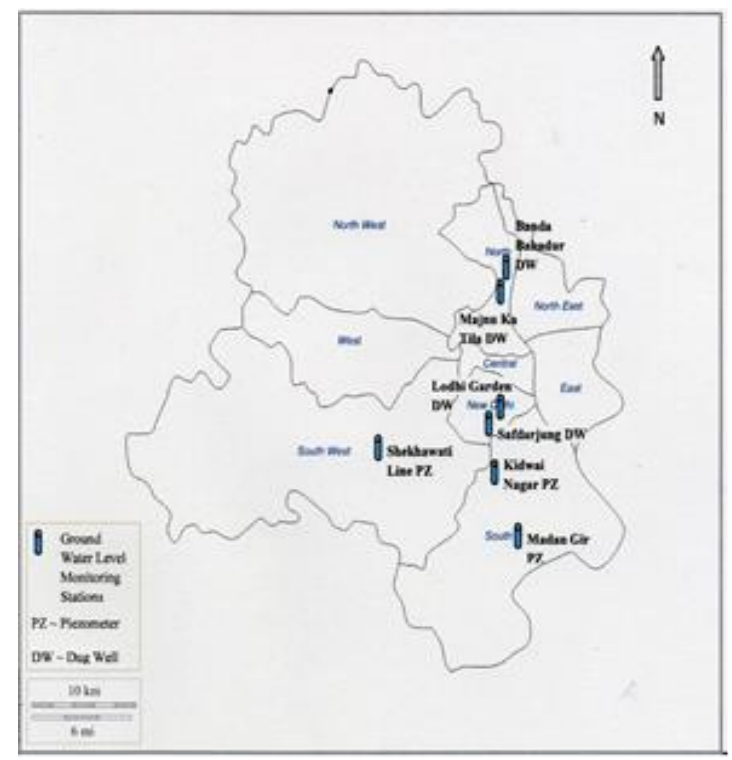

Figure 2. Location of Ground Water Level Monitoring Stations (Dug Wells and Piezometers) in NCT of Delhi
3. Some numerical information and facts have been gathered from Ground Water Year Book 2011-12, CGWB, New Delhi.

4. Data of urbanisation and population density of four selected districts have been taken from Economic Survey of Delhi 1991-1992, 20012002 and 2011-2012.

Current and potential ground water storage capacity of the four districts of NCT Delhi have been analysed in terms of their hydrogeological characteristics:

i. Physiography and Geology of NCT Delhi:

NCT Delhi consists of flat and level plains interrupted by cluster of longitudinal sand dunes and a long continuous chain of rocky ridges (CSE 2015).

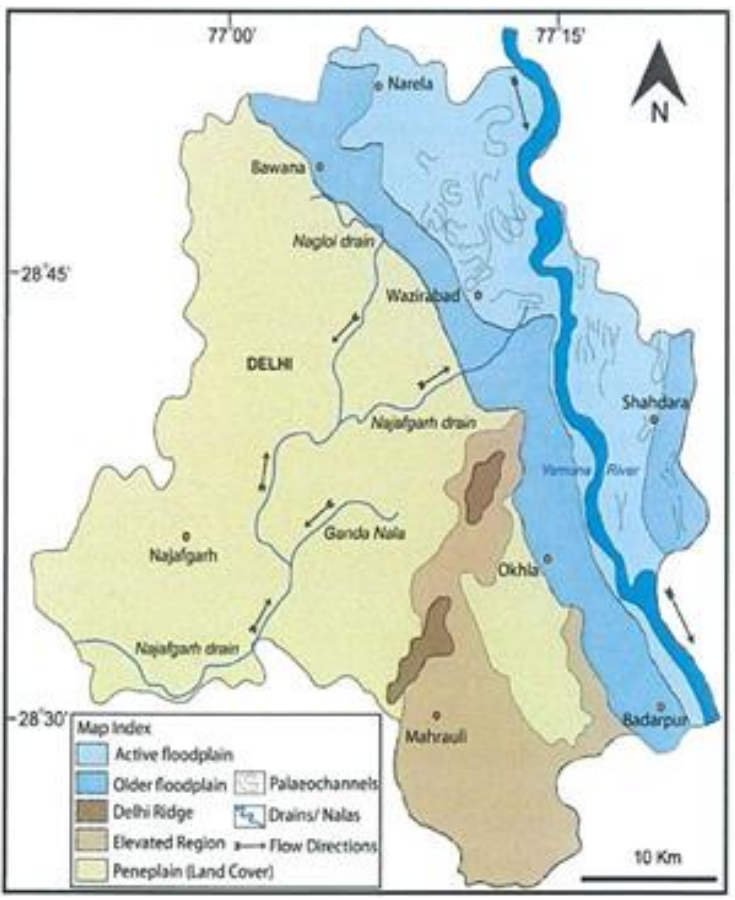

Figure 3. Geomorphological and Geological Map of NCT of Delhi

Source: Khan et al. 2014

Sand dunes generally lie between 6 and 15 metres above the surrounding plains, they are 
more or less fixed in this There are sand dunes of varying dimensions, aligned in northeast southwest direction. The crests of the area and support vegetation (Prabhakar, 2013). The chief physiographic divisions are as follows:

(a) Alluvial plain on eastern and western sides of the ridge.

(b) Yamuna flood plain deposits.

(c) Isolated and nearly closed Chattarpur alluvial basin.

(d) NNE-SSW trending Quartizitic Ridge.

Availability of the ground water in the territory is regulated by the hydrogeological situation (Figure 3 and Figure 4) characterized by occurrence of alluvial formation and quartizitic hard rocks. Aravalli Mountain consists of quartzite rocks and extends from southern parts of the territory to western bank of Yamuna for about 35 kilometers (Sharma 2010). The alluvial formations overlying the quartizitic bedrock have different nature on either side of the ridge- the Yamuna flood plain contains a distinct river deposit, whereas the nearly closed Chattarpur alluvial basin, covering an area of about $48 \mathrm{Km}^{2}$, is occupied by alluvium derived from the adjacent quartzite ridge (Rainwater Harvesting Org. 2012). Figure 3 shows that, geomorphology of New Delhi District is characterized by older flood plain of Yamuna, Delhi Ridge and associated elevated region. This Delhi ridge is actually the extension of Aravalli Hills. South-West Delhi is chiefly dominated by flat and level plains except some elevation region of Delhi Ridge in the extreme eastern portion. South Delhi mainly comes under the area of southern portion of Delhi Ridge and associated elevated area, only a narrow portion covering the middle and northern part of this district comes under plain land. Older and newer flood plain of Yamuna covers the major part of North Delhi district, except some of the southern portion under the elevated Delhi Ridge region.

ii. Climate: Being a small territory, all of the districts of NCT Delhi have almost similar types of climatic characteristics. The climate of all of the districts is mainly influenced by the inland position and prevalence of air of the continental type during major part of the year. Therefore, NCT Delhi has tropical steppe type of climate, marked with extreme temperatures (DDMA 2014-15). The cold season starts towards the latter half of November when both day and night temperatures drop rapidly with the advance of the season. January is the coldest month with the mean daily maximum temperature at $21.3^{\circ} \mathrm{C}$ and the mean daily minimum temperature at $7.3^{\circ} \mathrm{C}$. May and June are the hottest months. In May and June, maximum temperature may sometimes reach $46{ }^{\circ} \mathrm{C}$ or $47^{\circ} \mathrm{C}$. The rainy season in NCT Delhi begins in June and continues almost till October. NCT Delhi receives most of its rain during this period from the Northwesterly winds (Maps of India 2013).

Most of the precipitation occurs in the month of July. The average annual rainfall of each district varies between 600 to 700 millimeters out of which, $81 \%$ is received during the monsoon months of July, August and September. The rest of the rainfall is received as winter rain and as thunderstorm rain in the pre and post monsoon months (CGWB District Profile, New Delhi 2011). The variation of rainfall from year to year is large. On an average rain of $2.5 \mathrm{~mm}$ or more falls on 27 days in a year, of which, 19 days are during the monsoon months (Rainwater Harvesting Org. 2011). Two to three days in June are rainy. In other months, except in November and in first half of December when it is practically rainless, rain falls on a day or two only in each month.

iii. Soil: The soils of the NCT Delhi are mostly light with subordinate amount of medium texture soils (Rainwater Harvesting Org. 2012). The light textured The soil of New Delhi district is mostly calcareous in nature with clay, silt and fine to medium sand (CGWB District Profile, New Delhi 2011). Soils are sandy, loamy and sandy loam; whereas loam and silty loam represent medium textured soils. 


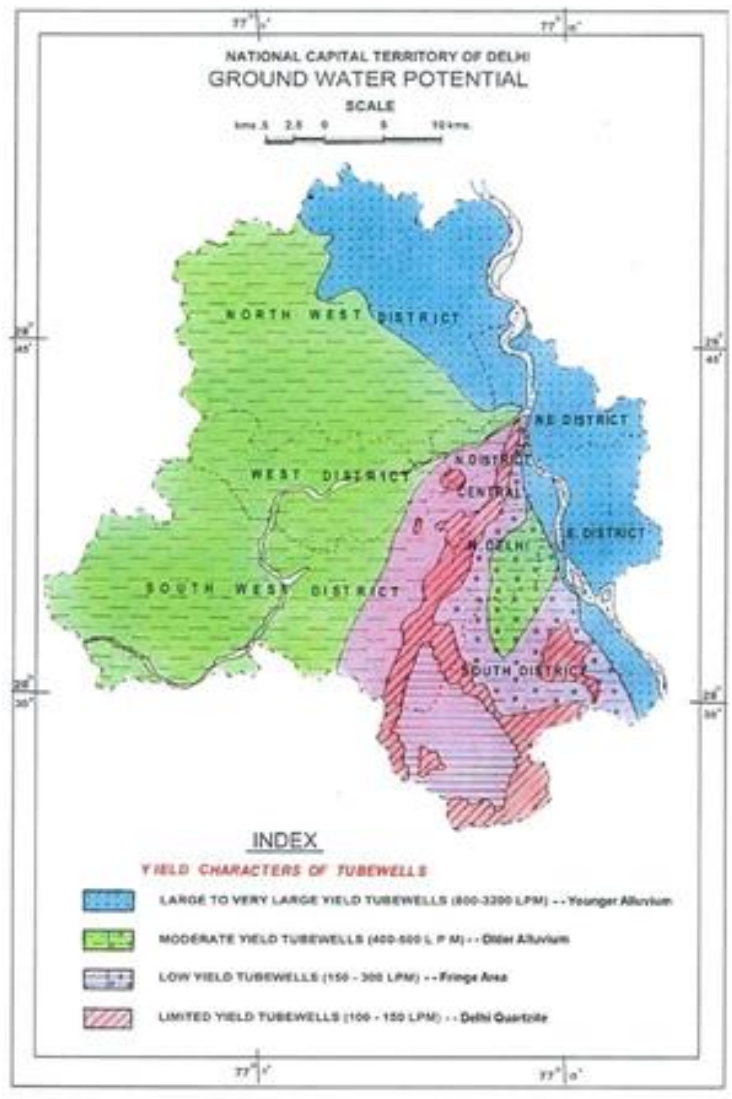

Figure 4. Ground Water Potential in NCT Delhi

Source: Shekhar et al. 2009

The soil of North Delhi has sand, silt and clay. Major soil types of the South and South-West Delhi are sand, clay and kankar.

iv. Potential Areas for Ground Water Recharge: Any type of anthropogenic activity or measures that input water to an aquifer system can be considered as an artificial recharge to ground water storage. It can be either planned in terms of digging a pit for the purpose of putting water into an aquifer, or it can be unplanned human activity e.g. surface water irrigation. The pre requisite conditions for undertaking artificial recharge to ground water are:
a) Favorable hydrological set-up
b) Developed aquifers
c) Ground water dependent community
d) Availability of unpolluted surface water

Analysing Figure. 4, it can be said that, the New Delhi comes under low to limited ground water potential, only the south-eastern part has moderate yield capacity. The South-West Delhi has moderate ground water potential, except in the eastern part where the yield capacity is low due to the presence of Delhi Ridge. Except along the narrow strip in the northern part, the entire South Delhi has low to limited potential of ground water. From north to south, the North Delhi district possesses high, moderate and low ground water storage respectively; along with poor water potential in the Delhi Ridge region. According to CGWB, exploitation of ground water is turning more and more areas into brackish to saline and the fresh water aquifers into brackish water. On the basis of the above criteria, South and South-West Delhi should be given priority in terms of artificial recharge to ground water to save these essential resources from over exploitation and promoting sustainable development.

Spatio-temporal fluctuation of ground water levels have been represented by ground water hydrographs. Hydrological year has been calculated based on the criteria of CGWB (New Delhi). Hydrological Year starts from 1st April / 31st May of a particular year to 30th April / 31st March of the subsequent year. Within this period, 1st April1 / 1st May to 30th September / 31st October is considered the Pre-Monsoon or Warm Period and; 1st October / 1st November to 31st March / 30th April is considered as Post-Monsoon or cold period.

i. Calculation for rainfall: Average rainfall $(\mathrm{mm})$ for Pre-Monsoon period has been calculated by adding monthly rainfall from May to October and for the average rainfall (mm) of Post-Monsoon period, monthly rainfall from November to April of the 2 subsequent years has been added.

ii. Calculation for ground water level: For PreMonsoon period the reading of $1 \mathrm{st}$ Nov. and for Post-Monsoon, the reading of 1st May has been taken as the ground water level. Reading dates 
regarding to the pre and post monsoon period have been considered as per the guidance by CGWB.

Now, both the values of average rainfall and ground water level have been plotted against each other to represent the relationship between these two variables for pre and post monsoon period. Thus hydrographs for 7 monitoring stations: Safdarjang Dug Well, Lodhi Garden Dug Well, Shekhawati Line Piezometer, Madan Gir Piezometer, Kidwai Nagar Piezometer, Banda Bahadur Dug Well and Majnu Ka Tila (MKT) Dug Well have been prepared. It may be pointed out that monitoring stations have been selected on the basis of their location in different parts of Delhi and on the basis of availability of long term consistent data from those stations.

\subsection{Limitations of this Study}

Following are the factors which have put some limitations on the present study:

1. Monthly rainfall data has been collected only from Safdarjang Weather Station of NCT Delhi because; 2005 onwards, IMD is not providing the rainfall data for Chandrawal, Okhla and Delhi University weather stations.

2. District wise distribution of monitoring stations is highly uneven. Among these monitoring stations, few are in a situation of taking reading for more than 20-25 years consistently because, stations get destroyed due to dumping, construction works etc. Therefore from each district one to two active monitoring stations have been selected for ground water level related data collection.

\section{RESULTS}

a) Ground Water Situation in New Delhi represented by Safdarjang and Lodhi Garden Dug Well:

Figure 5 and Figure 6 represent the rainfall and ground water level scenario of New Delhi district through Safdarjung Dug Well and Lodhi Garden Dug Well respectively for a period of 1990-91 to 2011-12. Figure 13 shows high rate of urbanisation in this capital area. Therefore, it can be summarised that, irrespective of high rainfall, high rate of urbanization and associated increase in buildup area have hindered the infiltration of rain water into the aquifer which is already poor in quality. Combination of the above situations has led to crisis situation near and around Safdarjang area where, ground water level has dropped to 20 MBGL or below even during the post monsoon season.

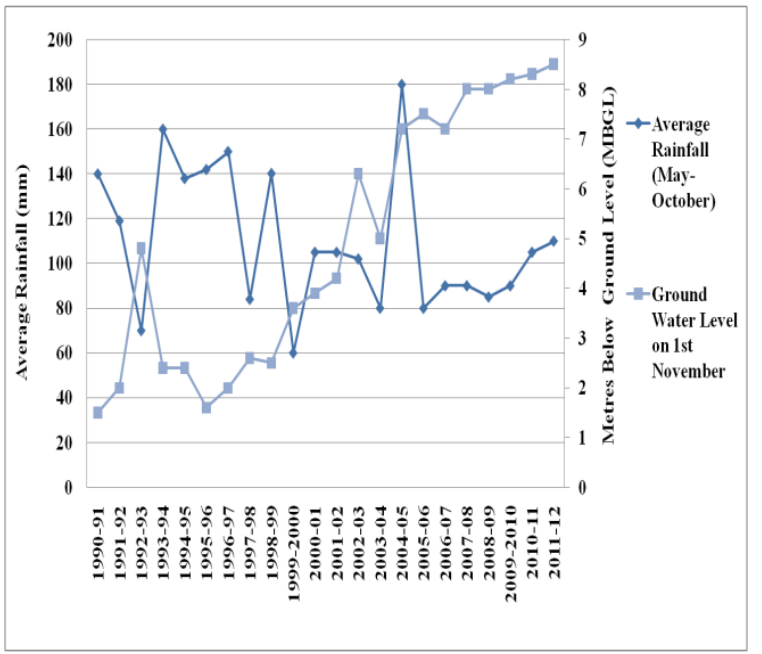

(A)

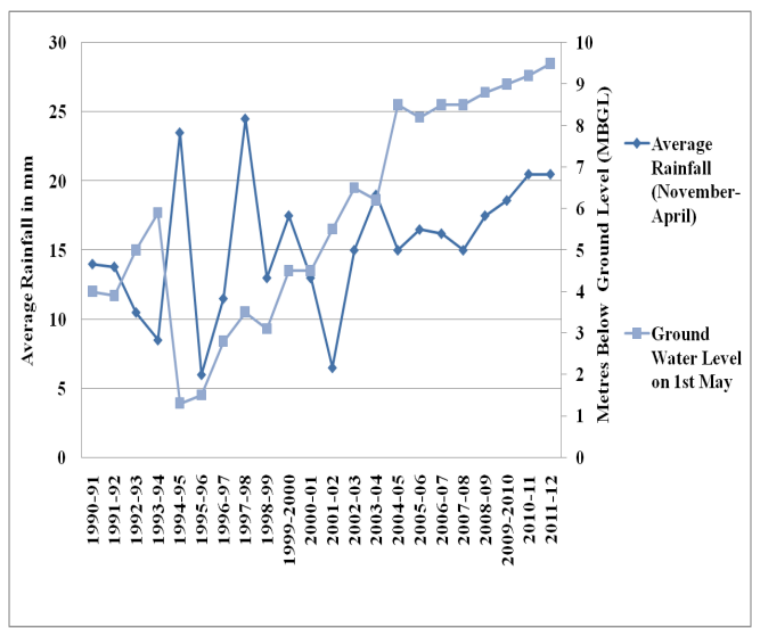

(B)

Figure 5. Pre-Monsoon (A) and Post-Monsoon (B) Ground Water Level Fluctuation in Safdarjang Dug Well (1990-91 to 2011-12) 
Relatively better situation can be found in Lodhi Garden area due to artificial recharge through injection wells - structures similar to a tube well but with the purpose of augmenting the ground water storage of a confined aquifer by pumping in treated surface water under pressure (CGWB, 2000). Here ground water level fluctuates between 8 to $10 \mathrm{MBGL}$ during pre and post monsoon period

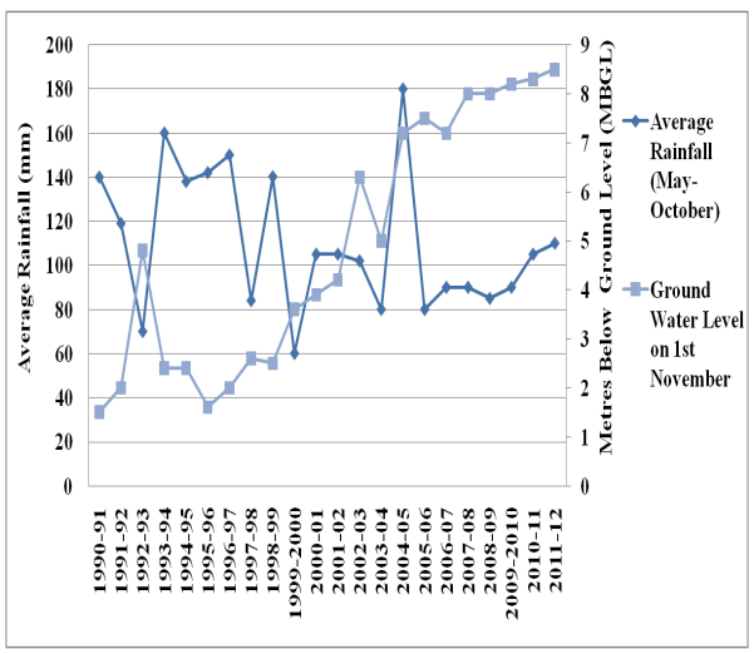

(A)

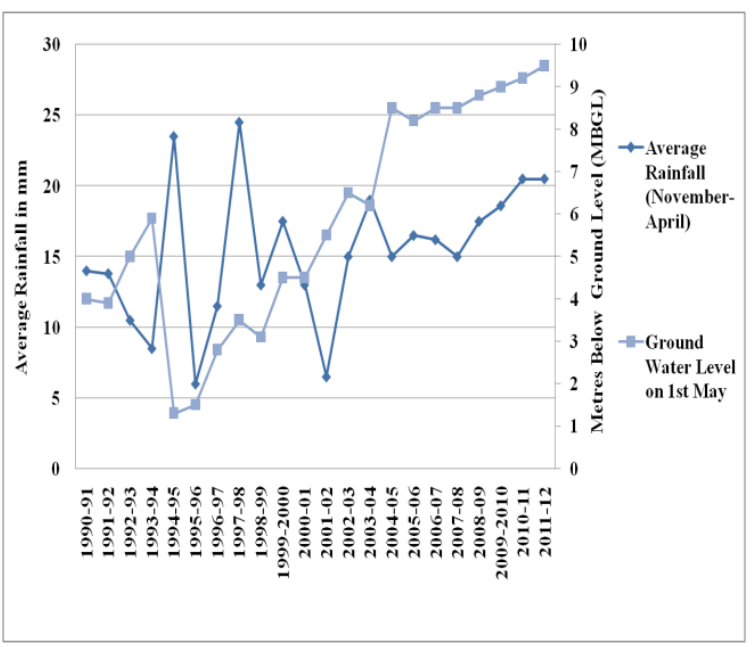

(B)

Figure 6. Pre-Monsoon (A) and Post-Monsoon (B) Ground Water Level Fluctuation in Lodhi Garden Dug Well

b) Ground Water Situation of South-West Delhi represented by Shekhawati Line Piezometer:
With respect to the water level behavior of Shekhawati Line Piezometer, South-West Delhi shows almost positive change of water level with rainfall during Pre-Monsoon Period (Figure 7A). However, during Post- Monsoon water level it records steady decline (Figure 7B) due to significant rate of urbanisation (Figure 13) accompanied by poor to moderate aquifer condition.

c) Scenario of South Delhi represented by Madan Gir Piezometer and Kidwai Nagar Piezometer:

After New Delhi, the South Delhi has the highest rate of urbanisation that disfavors infiltration (Figure 13). This district records the third highest rank in terms of population density among the four selected districts of NCT Delhi (Figure 12). The tanker mafia is also taking a toll on groundwater resources in South Delhi areas (Lalchandani, 2011) such as Green Park, Hauz Khas and Mehrauli where, the situation of ground water is already alarming (Figure 8 and Figure 9) due to high population density followed by high household demand.

Using illegal bore wells, they have been supplying water at exorbitant rates to a waterstarved city. South Delhi shows positive change of water level with rainfall during Pre-Monsoon Period (Figure 8A and Figure 9A). But during Post-Monsoon, water level records steady decline due to poor aquifer condition (Figure 8B and Figure 9B). In Kidwai Nagar Area, premonsoon ground water level fluctuation follows the trend of rainfall. But at the later period, water extraction reverses the situation (Figure 9A).

During post monsoon period, rainfall and ground water continue to show reverse relationship (Figure 9B), not only because of the previous stress but also due to low storage capacity of unconsolidated older alluvium and quartzite of Delhi super group (Figure 3 and Figure 4). 


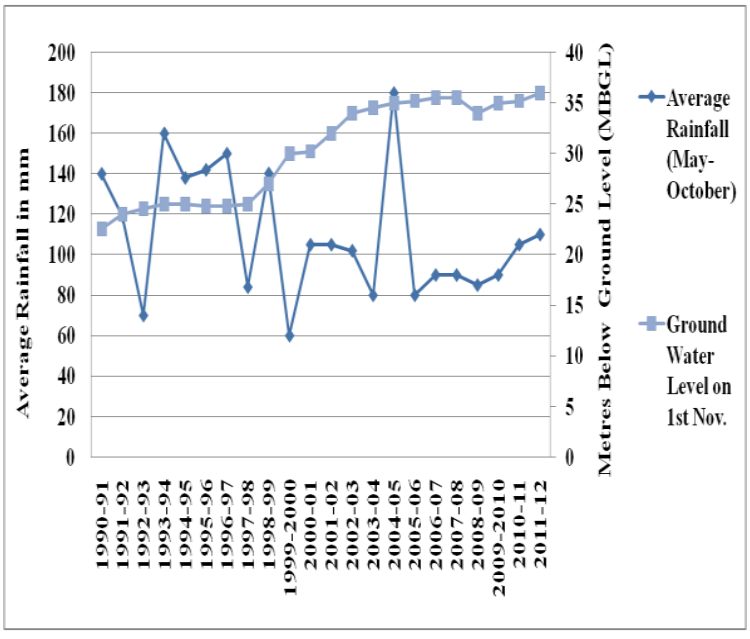

(A)

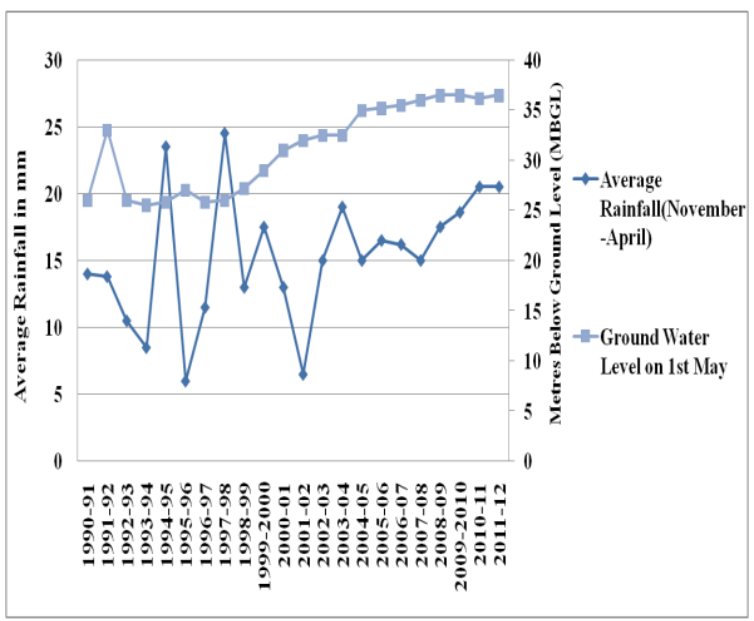

(B)

Figure 7. Pre-Monsoon (A) and Post-Monsoon (B) Ground Water Level Fluctuation in Shekhawati Line Piezometer

However, from 2003 onwards, the rain-water harvesting in Aurobindo Ashram and surrounding area $\left(95,870 \mathrm{~m}^{2}\right)$ have been improving the situation gradually. In this campus the rainwater from various catchments, including rooftop, surface runoff from open areas, is harvested. Rooftop rainwater harvesting is being operated in Mirambika School, Mother's International School, Tapsya Building and Office Block. Surface water harvesting is being done in the playground area and, near Mirambika School, Ashram Building and Power Sattion area (Rainwater Harvesting Org., 2003).

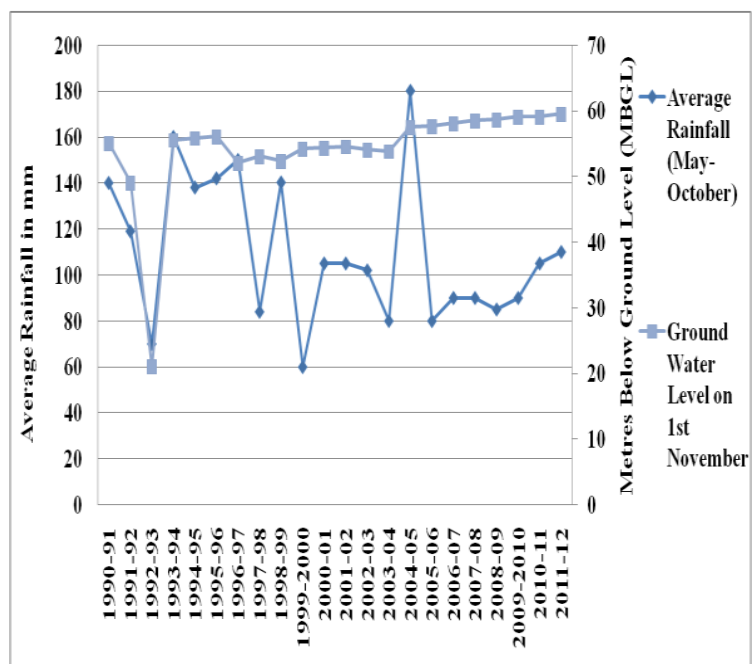

(A)

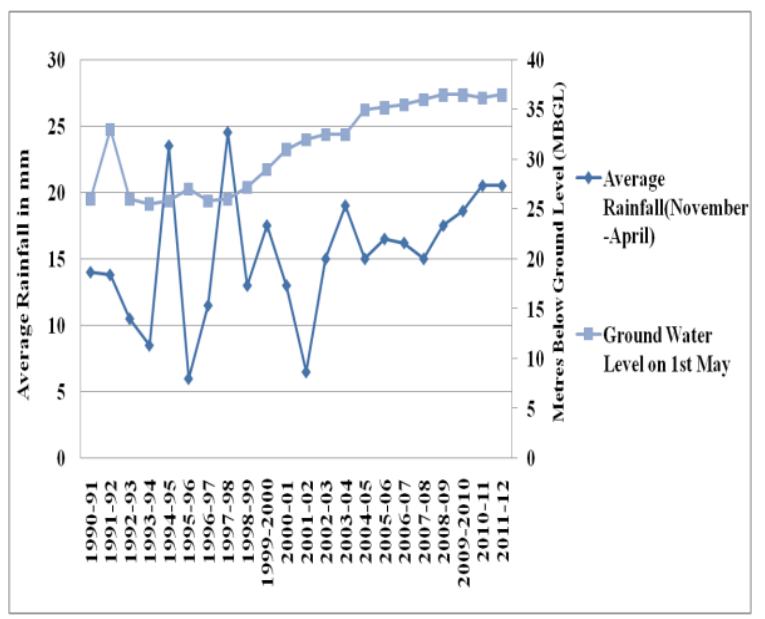

(B)

Figure 8. Pre-Monsoon (A) and Post-Monsoon (B) Ground Water Level Fluctuation in Madan Gir Piezometer

d) Situation in North Delhi-case study of Banda Bahadur Dug Well and MKT Dug Well:

During Pre-monsoon, water level of the area around and near Banda-Bahadur Dug Well fluctuates with rainfall (Figure 10A). After monsoon there is steady condition of ground water level as, majority of the North Delhi area acts as a vast recharge area (Figure 10B). Moreover this area comes under good reserve of ground water. Situation is worse in the area adjacent to MKT Dug Well (Figure 11) due to low ground water yield capacity, changed land 
use pattern, widespread constructions and water demand for firms and houses. This dug well represents the ground water level of the southern part of the North Delhi, which is close to Central Delhi and therefore has been preferred as residential area. This district has highest population density among the four districts selected for the present study. Shalimar Bagh, Punjabi Bagh, Shahdara, Khazoori Khas, Karawal Nagar, Commonwealth Games Village etc. are some of the densely populated residential area under MKT region.

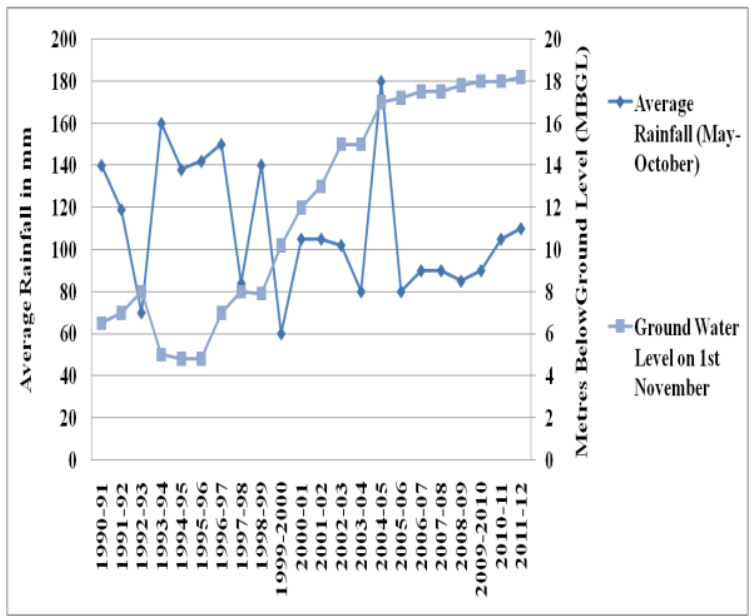

(A)

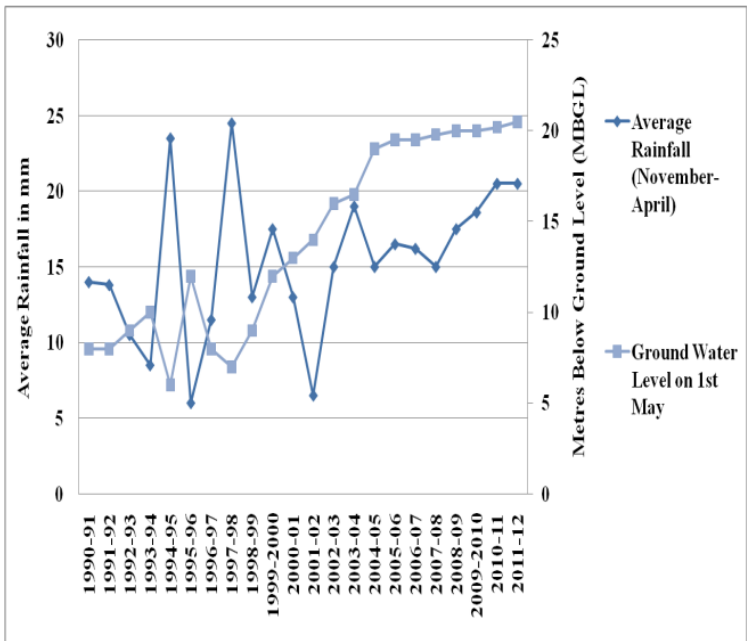

(B)

Figure 9. Pre-Monsoon (A) and Post-Monsoon (B) Ground Water Level Fluctuation in Kidwai Nagar Piezometer

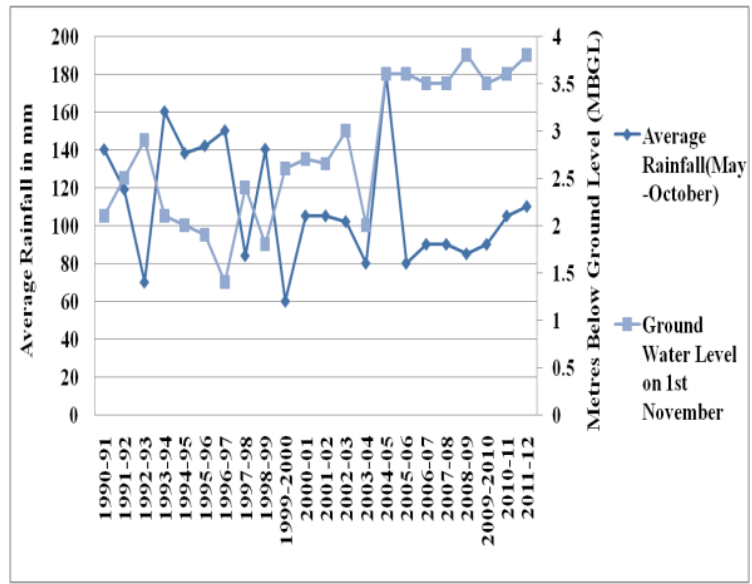

(A)

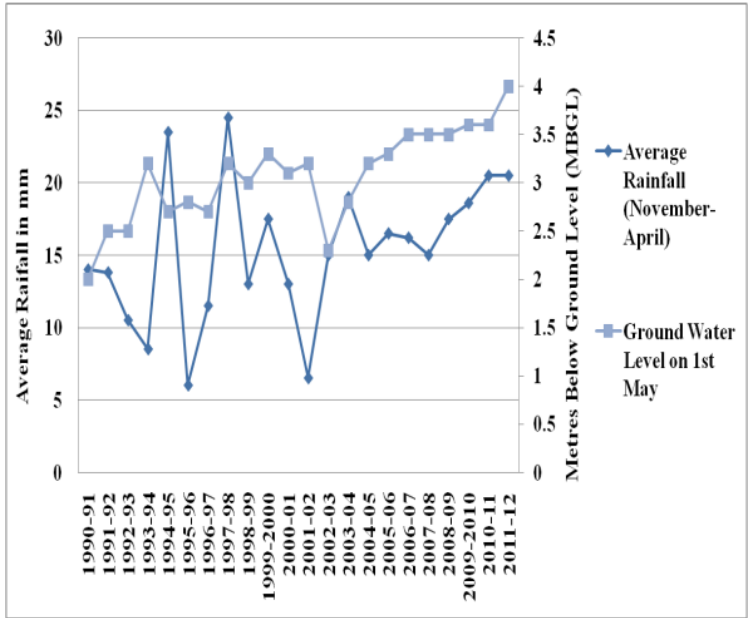

(B)

Figure 10. Pre-Monsoon (A) and Post-Monsoon (B) Ground Water Level Fluctuation in Banda Bahadur Dug Well

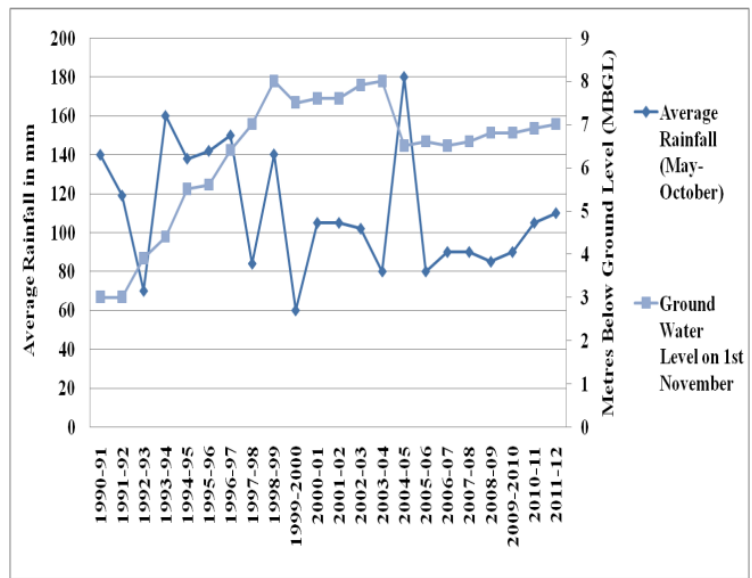

(A) 


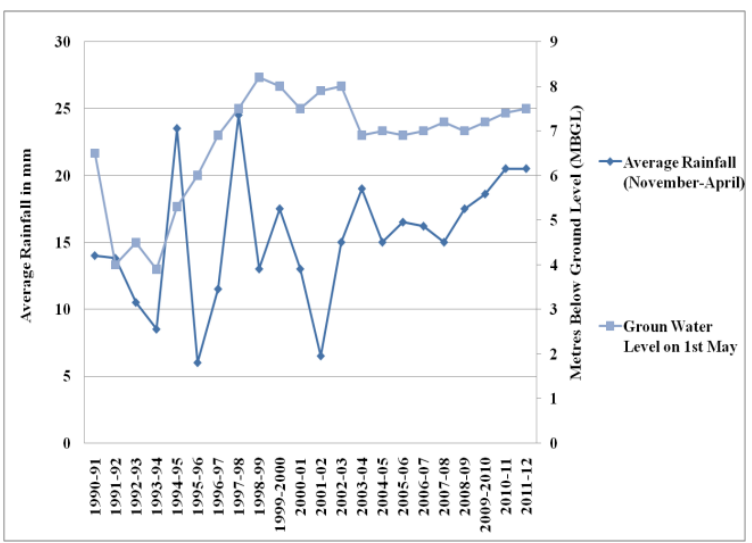

(B)

Figure 11. Pre-Monsoon (A) and Post-Monsoon (B) Ground Water Level Fluctuation in MKT Dug Well

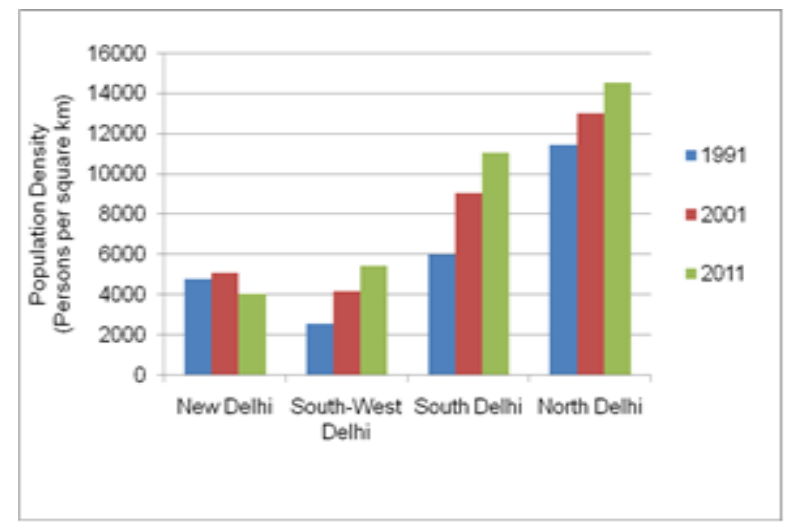

Figure 12. Population Density of Four Districts of NCT Delhi (1991-2011)

Source: Compiled from Economic Survey of Delhi 1991-1992, 2001-2002 and 2011-2012

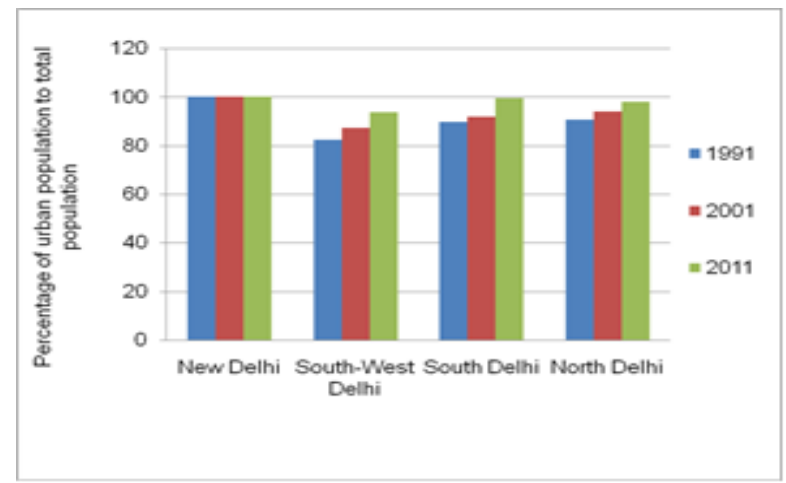

Figure 13. Urbanisation in Four Districts of NCT Delhi (1991-2011)

Source: Compiled from Economic Survey of Delhi 1991-1992, 2001-2002 and 2011-2012

\section{CONCLUSION \& RECOMMENDATIONS}

Falling groundwater levels of the study area has entered the danger zone and things are only getting worse by the day. At this rate, the Capital could be faced with a permanent water crisis soon. There is progressive lowering of groundwater levels due to pressures of urbanization followed by reduced natural recharge of aquifers, population, lack of proper recharge and illegal extraction of water. This study involves the ground water scenario of more than two decades. The worst-hit areas in terms of lowering of ground water table are, South Delhi and parts of Southwest Delhi.

New Delhi district has also been declared 'over-exploited areas' in terms of groundwater extraction. Other parts are relatively stable due to the facility of artificial recharge or natural recharge area. Keeping in mind increasing demand of water in the context of population growth, rapid rate of urbanization and climate change, Delhi government should take more active measures and implement planning to keep the ground water level under control.

The complex ground water regime of these districts of NCT Delhi requires scientific management and plans to make the ground water resources as sustainable source of water supply. Following groundwater management strategies can be followed:

1. Nourishment of Yamuna flood plain aquifers: Yamuna active flood plain aquifer system is well developed in Newer Alluvium, as it continues to remain unconfined to water level occurring at shallow depths of 3 to 7 MBGL. Around $90 \%$ to $95 \%$ area of North Delhi falls under new or active alluvial flood plain. Groundwater potential has been created by CGWB by installing tube wells throughout the Yamuna flood plain including North Delhi. Therefore, proper management and planning can further improve the yield of ground water from this area. 
2. Artificial Recharge to Groundwater: Rapidly growing population and rampant urbanisation are the root causes behind rapidly declining ground water level and reduction in the available open spaces i.e. recharge areas for groundwater in NCT Delhi. New, South, SouthWest and North Delhi districts receive 500 to $700 \mathrm{~mm}$. rainfall during monsoons but, some of the surface areas of these districts are covered by buildup areas and therefore, does not facilitate much infiltration and subsequent recharge of ground water.

Entire roof top rainwater is being channelized into Yamuna River. Conservation of most of the monsoon rain water should be done for the purpose of artificial recharge to groundwater. Government adopted the concept of artificial recharge and rainwater harvesting in The Master Plan of NCT Delhi which estimated that around 440 million metre $3 / a n n u m$ of rainwater can be harvested and utilized for artificial recharge to groundwater in NCT Delhi. The rain water harvesting can be done at the level of individuals, colonies and institutions. The CGWB of NCT Delhi has taken up the initiative and leadership of promoting rainwater harvesting in NCT Delhi.

The roof top rainwater harvesting effort by CGWB in JNU and IIT campuses of SouthWest Delhi have resulted in the rise in water level to the tune of about 2 to 3 meters in vicinity of the area where the project was implemented. Similar method was also adopted in President Estate of New Delhi, which resulted in the rise of water level in the range of 1 to 4 meters in the adjacent areas. Such initiative and the capital investment are required throughout the four districts of NCT Delhi for more satisfactory result.

3. Restrictions on Construction: The State Government has notified the whole NCT Delhi as area under regulation of ground water which only means that new tube wells cannot be built without the permission of the concerned authority. However, in order to regulate the over exploitation of ground water, construction of new ground water extracting structures should be prohibited especially in the critical areas. Delhi Government should enact comprehensive Ground Water Law or a Bill to regulate and control development of ground water should be prepared, enacted and implemented.

4. Construction of New Recharge Areas: Recharge structures can be a measure to improve the situation. Abandoned quarries, village ponds, urban forested areas, flood plains of Yamuna River etc. can be used as recharge structures by desilting ponds and creating artificial recharge pits .Trenches can be constructed along the Aravalli ridge for the purpose of rainwater harvesting.

5. Controlling Illegal Activities: Delhi Government should take strong legal steps to suppress the construction of illegal bore wells as well as the activities of tanker mafia.

\section{REFERENCES}

CENTRAL GROUND WATER BOARD (CGWB). Ground Water Information Booklet of New Delhi District, NCT Delhi. 2011. Accessed on http://cgwb.gov.in/District_Profile/Delhi/New \%20Delhi.pdf. Accessed on $18^{\text {th }}$ December 2015.

CENTRAL GROUND WATER BOARD (CGWB). Guide on Artificial Recharge to Ground Water. 2000. Available in http://cgwb.gov.in/documents/ArtificialRecharg A-Guide.pdf. Accessed on $15^{\text {th }}$ November 2014.

CENTRE FOR SCIENCE AND
ENVIRONMENT. Delhi: Climate and
Rainfall, Rainwater Harvesting Organisation,
CSE. Available r in
http://www.rainwaterharvesting.org/index files


/climate_rainfall.htm. Accessed on $12^{\text {th }}$ September 2013.

CENTRE FOR SCIENCE AND ENVIRONMENT. Delhi: Geology details, Rainwater Harvesting Organisation, CSE. Available in http://www.rainwaterharvesting.org/index_files /geology.htm. Accessed on 02 ${ }^{\text {nd }}$ April 2012.

CENTRE FOR SCIENCE AND ENVIRONMENT. Sri Aurobindo Ashram's System, Rainwater Harvesting Organisation, CSE. Available in http://www.rainwaterharvesting.org/catchwater/ april-may2003/cse_designs.htm. Accessed on $21^{\text {st }}$ November 2014.

CENTRE FOR SCIENCE AND ENVIRONMENT. Water Requirement and Sources of Water in Delhi Rainwater Harvesting Organisation, CSE. Available in http://delhibiz.co.in/rainwater-harvesting. Accessed on $21^{\text {st }}$ November 2014.

DELHI DISASTER MANAGEMENT AUTHORITY (DDMA) 2014-15. Delhi Disaster Management Plan (2014-15). Available in http://www.delhi.gov.in/wps/wcm/connect/8d9 93d004829d5ec8becebae1ccb7dea/Delhi+Draft +State+Plan+09042015+Part+I.pdf?MOD=AJP AJPE\&lmod $=-300925450$. Accessed on $20^{\text {th }}$ February 2016.

DELHI POLLUTION CONTROL BOARD. Action Plan Abatement of Pollution in Critically Polluted Area of Najafgarh Drain Basin Including Okhla, Naraina, Anand Parbat and Wazirpur Indl Areas. 2011. Available in http://cpcb.nic.in/divisionsofheadoffice/ess/Del De. Accessed on $20^{\text {th }}$ November 2012.

KHAN A \& BAJPAI VN. Constriction of The Yamuna River Floodplains Within Delhi Region Since 19th Century: A Serious Concern, International Journal of Research in
Engineering and Technology. 2014; 3(9): 430436.

LALCHANDANI N. Water Scarce, Groundwater Level's Dipping, Times of India. 2011. Accessed on $2^{\text {nd }}$ February 2012.

SHEKHAR S, PUROHIT RR \& KAUSHIK YB. Groundwater Management in NCT Delhi, Technical Paper Included in the Special Session on Groundwater in the 5th Asian Regional Conference of INCID. 2009; 01 - 10. Available in CGWB Portal. Accessed on $01^{\text {st }}$ March 2015.

MAPS OF INDIA. Delhi: Delhi Geography, Maps of India. Accessed on http://www.mapsofindia.com/delhi/geography. html. Accessed on $28^{\text {th }}$ October 2015.

PRABHAKAR P. Rainwater Harvesting, $8^{\text {th }}$ November 2013. Pieyush Prabhakar Blog. Available in http://rwaterharvesting.blogspot.in. Accessed on $23^{\text {rd }}$ February 2014.

SHARMA SK. Rooftop Rainwater Management - A Key to Resolve Water Crisis in India', Novatech $2010-7^{\text {th }}$ International Conference on Sustainable Techniques and Strategies for Urban Water Management. 2010; 1-10. Available in I-Revues Portal. Accessed on $20^{\text {th }}$ February 2012. 